\title{
Sentidos de la militancia en Argentina y Brasil: análisis de los significados asignados al compromiso político en tres generaciones de militantes*
}

\author{
Senses of Militancy in Argentina and Brazil: Analysis of the Meanings \\ Assigned to Political Commitment in Three Generations of Militants \\ Sentido de militância na Argentina e no Brasil: análise dos \\ significados atribuidos ao compromisso político em três gerações de \\ militantes
}

Recibido el 2 de junio de 2017. Aceptado el 11 de diciembre de 2017

Dolores Rocca Rivarola**

Argentina

, Para citar este artículo:

Rocca Rivarola, Dolores (junio,

2018). Sentidos de la militancia

en Argentina y Brasil: análisis

de los significados asignados

al compromiso político en tres

generaciones de militantes.

Ánfora, 25(44), 205-231.

Universidad Autónoma de

Manizales. ISSN 0121-6538.

\section{Resumen}

Objetivos: identificar, apartir del análisiscomparativo, las concepciones del compromiso político en la militancia oficialista en los gobiernos kirchneristas (2003-2015) en Argentina y del Partido de los Trabajadores (20032016) en Brasil. Metodología: desde una perspectiva cualitativa, se abordaron tres grupos de militantes mediante 28 entrevistas semiestructuradas realizadas entre 2005 y 2015, según un criterio generacional:

\footnotetext{
* El presente trabajo analiza material empírico producido a lo largo de distintas investigaciones. Primero, entre 2005 y 2011, para la tesis doctoral "En torno al líder: Relaciones y definiciones de pertenencia dentro de los conjuntos oficialistas de Luiz Inácio Lula Da Silva (2002-2006) y Néstor Kirchner (20032007)". Y luego, para una investigación posdoctoral iniciada en 2012 y aún en curso sobre la militancia en organizaciones oficialistas en Argentina y Brasil, actualmente en el marco del proyecto UBACyT (20162017) que dirige la autora "La transformación del vínculo militante. Fenómenos de nostalgia, adaptación y militancia desde el Estado en organizaciones oficialistas en Argentina y Brasil desde 2003". Asimismo, se inscribe desde 2015 en las investigaciones del Equipo.

** Doctora en Ciencias Sociales. Licenciada en Ciencia Política. Investigadora Asistente del Consejo Nacional de Investigaciones Científicas y Técnicas (CONICET), en el Instituto de Investigaciones Gino Germani, de la Universidad de Buenos Aires. Integrante del Equipo de Estudios de Políticas y Juventudes (EPOJU). Correo: doloresrocca@gmail.com
} 
el momento histórico de inicio de su militancia juvenil (años 80, 90 y hasta 2002 y, finalmente, quienes se iniciaron en la militancia política luego de la llegada de Kirchner y Lula al poder). Resultados: dos ejes aparecieron con regularidad en los testimonios. En primer lugar, los sentidos asociados a la militancia en los que se advirtió una diferenciación marcada entre generaciones, sobre todo con definiciones respecto de un pasado con vínculos más estables, mayores niveles de compromiso, predisposición militante y formación política. En segundo lugar, la cuestión de la militancia en el marco de la inserción gubernamental de las organizaciones de pertenencia, con el fenómeno de profesionalización militante y las modalidades de articulación entre la función pública y las tareas político-organizativas. Conclusiones: en el primer eje, el análisis comparativo entre generaciones militantes se perfiló como una clave sugerente para pensar las transformaciones del vínculo político, las prácticas y las concepciones sobre la militancia. En el segundo eje, aunque el análisis por generaciones de militancia juvenil arroja conclusiones sugerentes respecto de las concepciones y tensiones intergeneracionales, algunas lecturas y sentidos atravesaban a los tres grupos, y dependían más bien de la organización de pertenencia.

Palabras clave: Militancia; Estado; Gobierno; Argentina; Brasil.

\section{Abstract}

Objective: to identify, based on comparative analysis, the conceptions of political commitment in official militancy during the Kirchnerist governments (2003-2015) in Argentina and the Workers' Party (2003-2016) in Brazil. Methodology: from a qualitative perspective, three groups of militants were approached through 28 semistructured interviews carried out between 2005 and 2015, according to a generational criterion: the historical moment of the beginning of their youth militancy (years 80,90 and until 2002 and, finally, those who started in political militancy after Kirchner and Lula came to power). Results: two axes appeared regularly in the testimonies. Firstly, the senses associated with militancy in which a marked differentiation between generations was observed, especially with definitions of a past with more stable links, greater levels of commitment, militant predisposition and political formation. Secondly, the question of militancy within the framework of the governmental insertion of member organizations, with the phenomenon of militant professionalization and the modalities of articulation between public service and political-organizational. Conclusions: in the first axis, the comparative analysis between militant generations was outlined as a suggestive key to think about the transformations of the political link, practices and conceptions about militancy. In the second axis, although the analysis by generations of youth militancy draws suggestive conclusions regarding intergenerational conceptions 
and tensions, some readings and senses cut across the three groups, and depended rather on membership organization.

Keywords: Militancy; State; Government; Argentina; Brazil.

\section{Resumo}

Objetivo: identificar, a partir da análise comparativa, as concepções do compromisso político na militância oficialista nos governos kirchneristas (2003-2015) na Argentina e do Partido dos Trabalhadores (2003-2016) no Brasil. Metodologia: a partir de uma perspectiva qualitativa, três grupos de militantes foram abordados através de 28 entrevistas semi - estruturadas realizadas entre 2005 e 2015, de acordo com uma abordagem geracional: o momento histórico do início de sua militância juvenil (anos 80, 90 e até 2002, e, finalmente, quais deles foram iniciados em ativismo político depois da chegada de Kirchner e Lula ao poder). Resultados: dois eixos apareceram com regularidade nos testemunhos. Primeiro, os sentidos associados à militância no quais se advertiu uma diferenciação acentuada entre as gerações, especialmente com as definições a respeito de um passado com laços mais estáveis, níveis mais elevados de comprometimento, vontade militante e formação política. Em segundo lugar, a questão da militância no âmbito da inserção governamental das organizações pertencentes ao fenômeno da profissionalização militante e as modalidades de articulação entre a função publica e as tarefas politico- organizacionais. Conclusões: no primeiro eixo, a análise comparativa entre as gerações militantes surgiu como uma chave sugestiva para pensar as transformações das relações políticas, práticas e concepções de militância. No segundo eixo, embora a análise por gerações de militância juvenil lance conclusões sugestivas sobre concepções e tensões intergeracionais, algumas leituras e sentidos atravessaram os três grupos, e dependem mais, sobretudo, da organização da sociedade.

Palavras-chave: Militância; Estado; Governo; Argentina; Brasil. 


\section{Introducción}

La militancia política en su modalidad oficialista no constituye un fenómeno novedoso o reciente. Los gobiernos construyen, más temprano o más tarde, de modo más sólido y estructurado o más endeble e informal, bases de sustentación activa que desarrollan demostraciones públicas de apoyo organizado a esas gestiones. En el caso de los gobiernos de Néstor Kirchner y Cristina Fernández de Kirchner (2003-2015) y las administraciones de Luiz Inácio Lula da Silva y Dilma Rousseff (2003-2016, hasta la destitución de ésta), se asiste, sin embargo, a escenarios especialmente ricos para analizar la militancia oficialista y los sentidos asignados por sus protagonistas.

Ello, por la considerable visibilidad que adquirieron esas masas militantes en el marco de los gobiernos mencionados y por las similitudes advertidas en el debate público en ambos países (y en el tipo de acusaciones vertidas desde la oposición) acerca de las articulaciones entre militancia y Estado. Y, por otro lado, se trata de dos casos disímiles en términos de la composición interna y tradiciones políticas presentes en el interior de esos conjuntos oficialistas.

Como se verá en la sección metodológica, tales diferencias ameritan muestras también distintas, con pesos relativos específicos del Partido de los Trabajadores (PT) y del Partido Justicialista (PJ), así como de otras organizaciones por fuera de esas estructuras, especialmente en el caso argentino, donde, sobre todo en los últimos de los gobiernos kirchneristas, el oficialismo se caracterizó por la afluencia (y ponderación) de una galaxia de organizaciones fuera del PJ, algunas de ellas incluso ajenas a la tradición peronista.

Inscribiéndose en la literatura que plantea el debilitamiento de los vínculos estructurales y psicológicos entre los partidos y los ciudadanos, este trabajo postula la pertinencia de estudiar la militancia política activa atendiendo al hecho de su persistencia, e incluso de su crecimiento. En otros términos, aunque la volatilidad electoral y la fluctuación en las identidades políticas sean fenómenos ya característicos de los formatos de representación en Argentina y Brasil (y de notable intensidad durante los gobiernos en cuestión), la militancia sigue siendo una actividad significativa al interior de las organizaciones políticas, aunque haya sufrido un impacto en las condiciones en que se desenvuelve y en los sentidos y concepciones que tienen sobre la misma los propios actores ${ }^{1}$.

1- En trabajos previos, se he analizado dos dimensiones de ese impacto: la adaptación práctica a las condiciones de fluctuación, a través la transformación del propio vínculo militante (Rocca Rivarola, 2015) y, paralelamente, la exhibición, en las narrativas de los entrevistados, de referencias nostálgicas a un pasado de identidades partidarias arraigadas (Rocca Rivarola, 2017). 
Partiendo de aquel diagnóstico, este artículo se propone analizar los modos en que militantes de las bases de sustentación activa de los gobiernos kirchneristas y del PT concebían el compromiso político. El trabajo vincula, así, tres dimensiones de análisis. En primer lugar, se examina un tipo de militancia específico, la militancia oficialista (y sus derivaciones en términos de la inserción estatal). En segundo lugar, al tomar una muestra de tres grupos etarios de activistas, cotejarlos según un criterio generacional (su momento de incorporación a la militancia juvenil) e identificar sus concepciones respectivas (y recuerdos) sobre la militancia en cada uno de esos períodos, se introduce un elemento diacrónico y se procura contribuir al debate sobre las transformaciones de la militancia política en las últimas décadas. En tercer lugar, los ejes temáticos delineados permiten dar cuenta de diferentes generaciones (y sus concepciones) de activismo juvenil.

Dadas las tres dimensiones de análisis mencionadas -la transformación del vínculo político, la militancia juvenil y la oficialista-, cabe relevar algunas discusiones de la literatura, especialmente desde Argentina y Brasil, sugerentes para abordar los interrogantes planteados. Primero, los trabajos que refieren a las mutaciones en el formato de representación política desde la redemocratización. Segundo, estudios que analizan específicamente la cuestión del vínculo entre juventud y política. Y, tercero, las investigaciones que se ocupan de la militancia en el marco de un vínculo con el Estado.

El primer grupo de trabajos hace alusión a un diagnóstico de mutación del lazo político (Manin, 1992), con una erosión de la identificación partidaria en los votantes (ya raramente fieles en su voto a una misma fuerza a lo largo del tiempo), la caída en los niveles de afiliación, y la posibilidad de los líderes políticos de prescindir de los cauces partidistas tradicionales a la hora de establecer un vínculo identitario con sus votantes (Montero y Gunther, 2002; Norris, 2007). Esas transformaciones en el vínculo político y las identidades han sido examinadas también para Argentina (Pousadela y Cheresky, 2004; Svampa, 2009) y para Brasil, aunque, en torno a ese caso, distintos autores han asociado esa misma fisonomía de la representación no a transformaciones recientes, como en Argentina, sino a una configuración histórica más antigua (Mainwaring y Torcal, 2005; Pousadela, 2007). De todos modos, se ha observado desde la transición democrática (1985) una progresiva profundización de esas tendencias, con una escena político-electoral contingente, campañas electorales centradas en los candidatos individuales, altos niveles de volatilidad electoral, migraciones partidarias en las bancadas parlamentarias (Mainwaring y Torcal, 2005; Carreirão, 2008, Nicolau, 2015), y una creciente desafección con los partidos en general. Incluso con el propio PT, aunque éste sea en ocasiones sindicado como una suerte de excepción, como un partido que lograba un voto orgánico 
por el propio sello partidario [legenda] más allá de sus liderazgos (Kinzo, 2005; Lacerda, 2002 $)^{2}$. A partir de los aportes relevados acerca de las transformaciones en el lazo entre electores y partidos, este trabajo se inserta en ese debate, para indagar un aspecto más específico y menos abordado en la literatura: lo ocurrido en ese contexto con el vínculo militante.

Un segundo grupo de investigaciones de las que este artículo se nutre se dedica a las prácticas políticas juveniles, abarcando desde estados del arte (Bonvillani et al., 2008) hasta estudios de caso sobre la participación política juvenil reciente en ambos países. Por ejemplo, en Argentina, los trabajos de Garrido (2012), sobre la participación política juvenil a través de las nuevas tecnologías de la información y la comunicación (TICs); Vázquez y Vommaro (2012), sobre la militancia en una agrupación autoconcebida como juventud del kirchnerismo, La Cámpora; y Vázquez, Rocca Rivarola y Cozachcow (2016), que construyen perfiles de militantes juveniles del Movimiento Evita, el PRO y el Partido Socialista. Y, para el caso de Brasil, Mische (1997) analiza los procesos de construcción y reformulación identitaria al interior de la movilización política juvenil por el juicio político a Collor en 1992; Marques (2016) investiga, en su tesis, a la juventud partidaria del PT; Brenner (2011) indaga en las experiencias de aquellos jóvenes que han optado por el activismo partidario tradicional y, finalmente, Rocha (2009) estudia los contrastes y puntos de confluencia entre las lógicas organizativas, modos de inserción y prácticas de la militancia juvenil del PT en Brasilia en el pasado y en el presente. De modo similar a Rocha, el presente trabajo compara distintas generaciones de juventudes militantes, pero cotejando, a su vez, dos casos nacionales.

Un tercer grupo de estudios a relevar reflexiona sobre la militancia en el marco de un vínculo con el Estado ${ }^{3}$. Esas discusiones podrían organizarse en torno a distintos ejes temáticos.

Un primer eje es la cuestión de la composición de la administración pública, específicamente, la proporción entre cargos ocupados por los denominados funcionarios de carrera y las designaciones políticas. En Brasil, autoras como Pacheco (2002) y Lameirão (2009) critican la visión maniquea de algunos organismos internacionales de un perfil de técnicos "buenos" y políticos "malos" ocupando cargos públicos, y sostienen que, desde los años noventa la

\footnotetext{
2. Las transformaciones sufridas específicamente por el PT y el peronismo desde la redemocratización han sido analizadas, asimismo, por Gutiérrez (2001), Levitsky (2003), para Argentina; y Samuels (2004), Amaral, (2010) y Secco (2011), para Brasil, o incluso comparativos (Rocca Rivarola, 2011).

3. La propuesta de este trabajo no es un análisis del carácter del Estado. Por lo tanto, se ha evitado presentar una conceptualización sobre su naturaleza. En los testimonios de los actores, incluso, el Estado aparece concebido de variadas formas (espacio a disputar, cúmulo de reglas y prácticas, mecanismo de transformación social), con lo cual tampoco cabría una definición como hallazgo.
} 
fuerza de trabajo federal brasilera ha tenido más bien una composición híbrida (combinando distintos criterios políticos, técnicos y de confianza personal) ${ }^{4}$. Con base en el análisis de la composición del empleo público para el caso argentino, por otro lado, distintos trabajos recientes se han interrogado sobre los vínculos entre burocracia, expertos y política electoral, como el uso del Estado y de sus recursos como fuente de financiamiento de aparatos partidarios (Moscovich, 2016; Oliveros, 2016).

Un segundo eje temático de la literatura en torno a la militancia y el Estado engloba las reflexiones acerca del posible aporte de la impronta militante sobre la gestión y políticas públicas, tanto las interrogaciones sobre cómo su presencia resignifica prácticas estatales (Perelmiter, 2012; Vázquez, 2015, para Argentina), como también sobre la influencia y rol de distintos movimientos sociales en el impulso e implementación de políticas de ampliación de derechos y participación ciudadana (Dagnino, Olvera y Panfichi, 2006; Levy, 2012, para Brasil). El propósito del presente trabajo es, en algún sentido, inverso: más que por el impacto de la presencia militante sobre el Estado, se pregunta por las características de las concepciones militantes al desarrollarse en un marco de inserción estatal.

Y el tercer eje temático que es de particular interés para pensar la militancia en el marco del Estado involucra diferentes conceptualizaciones posibles acerca de los vínculos existentes entre organizaciones militantes y Estado. En su estado del arte, Silva y Oliveira (2011), parten de una crítica a las interpretaciones que se valen de las nociones de cooptación, instrumentalización y colonización de los movimientos sociales por parte del Estado y relevan otras propuestas conceptuales, como la noción de "intersección Estado-movimientos", o incluso la idea de "apropiación institucional" de Tarrow (2001), imagen que habilita la posibilidad de pensar, de modo más completo, la relación organizaciones militantes-Estado, tomando en cuenta un elemento en ocasiones subestimado en algunos estudios argentinos: el impacto que la inserción institucional puede tener sobre la capacidad de crecimiento de la organización de pertenencia, cuyos miembros ahora cuentan con un vínculo laboral, un salario e incrementada presencia en el territorio.

Considerando los avances ya realizados por los distintos estudios recorridos, este trabajo combina las tres dimensiones de análisis -militancia oficialista, activismo juvenil y transformación del vínculo político-planteando los siguientes interrogantes: ¿Qué sentidos e implicancias de la militancia emergían en las narrativas de los entrevistados al referirse a su propio activismo político juvenil

4. Ello, especialmente, al interior de los "Cargos de Direção e Assessoramento Superior" (DAS), que, al ser "cargos de confianza", son de designación libre (livre nomeação) y no siguen el procedimiento que rige gran parte del acceso a la burocracia federal en Brasil, el concurso público. 
(en la actualidad o en el pasado, según el período de inicio de sus trayectorias militantes)? ¿Cómo era concebida la militancia, ya en el presente, en el marco de la inserción estatal de la organización de pertenencia o del mismo militante?

Finalmente, cabría precisar conceptualmente qué se entiende en este trabajo por la figura del militante. En primer lugar, y a partir de los círculos concéntricos de Duverger (1957), en los que los “militantes” eran el círculo nuclear y más restringido de afiliados activos e involucrados en las actividades partidarias, se debería, para los oficialismos brasilero y argentino, reformular la definición. Ello, teniendo en cuenta los casos de numerosas organizaciones militantes kirchneristas argentinas que no se estructuraron como partidos (ni llamaron a sus miembros a afiliarse a alguno) y que ni siquiera contaban con padrones formales de afiliados. O la situación, asimismo, de muchos afiliados al PJ y al PT que habían dejado de militar en esos partidos años atrás y participaban, en cambio, en organizaciones al margen de éstos, pero sin desafiliarse de los mismos.

Frente a ello, la definición de Quirós (2014) permite incluir esa diversidad, señalando al militante como aquel que "integra y participa, de forma orgánica y activa, en una organización política, partidaria o de otro tipo" (Quirós, 2014, p. 251). Es decir, la militancia política planteada como la pertenencia o comportamiento orgánico, más allá de la inscripción formal en la organización de pertenencia o en un partido. En segundo lugar, la noción de militante presente en este trabajo se basa, en gran medida, en la definición acuñada por los propios actores. En ese sentido, la autoidentificación primaria como militantes era generalizada entre los entrevistados, incluso entre dirigentes, legisladores (de cualquier nivel) y funcionarios jerárquicos del Estado. Como resultado, se entiende aquí al militante no estrictamente como el activista de base, sino de un modo más amplio e incluyente de esas otras posiciones.

\section{Metodología}

El trabajo adopta una perspectiva metodológica cualitativa, recuperando las interpretaciones de los propios actores a través del análisis de entrevistas semiestructuradas realizadas entre 2005 y 2015 en cuatro localidades: en Brasil, las ciudades de San Pablo y Río de Janeiro; y, en Argentina, la ciudad de Buenos Aires y algunos distritos del conurbano bonaerense -con especial foco en La Matanza $^{5}$.

\footnotetext{
5. En Argentina, el trabajo de campo, continuo, ha tenido lugar en dos períodos: entre 2005 y 2010; y, luego, entre 2013 y 2015. En Brasil, el trabajo de campo fue desarrollado en el marco de cuatro viajes. Primero, en 2008, a San Pablo, y en 2009, a Río de Janeiro, y, luego, en el marco de dos estadías de investigación
} 
Del total de 129 entrevistas realizadas en el período en cuestión ( 74 en Brasil y 55 en Argentina), este trabajo utilizó una muestra de 28 casos, a los que se ha dividido en tres grupos según el momento de inicio de su propia militancia juvenil ${ }^{6}$. Se configuran, por tanto, tres generaciones. En primer lugar, la que se incorporó a la política activa en la década del ochenta, es decir, en los últimos años de la dictadura militar y albores de la democratización en ambos países, momentos, asimismo, de reactivación de los partidos políticos, de afiliaciones masivas en Argentina, y años fundacionales del propio PT y de otras organizaciones en Brasil, como la Central Única de Trabajadores (CUT) y el Movimiento de Trabajadores Rurales Sin Tierra (MST). En segundo lugar, la generación que comenzó a militar en los años noventa y hasta la crisis argentina de 2001/2002 y el triunfo electoral de Lula (2002).

Este grupo incluye, entonces, en Argentina, a quienes se incorporaron a la militancia juvenil durante la década menemista y los años de crisis económica y política de los gobiernos de De La Rua y Duhalde, así como en el marco de una serie de cambios en el propio peronismo (escisión del Grupo de los Ocho y mutaciones en su composición interna social y sectorial). Y, en Brasil, a quienes comenzaron su activismo en una década que incluyó la crisis y renuncia de Collor de Melo, los años de reformas estructurales de Cardoso, y las transformaciones organizativas, tácticas y programáticas al interior del PT. Y, finalmente, una tercera generación, que se denomina aquí “pos 2003”, de quienes se iniciaron en la militancia política juvenil con posterioridad a la llegada de Kirchner y Lula al poder. Es decir, quienes inauguraron sus trayectorias militantes ya como parte de esos conjuntos oficialistas a los que todos los entrevistados (de las tres generaciones) pertenecían al momento de ser consultados ${ }^{7}$.

El mapa de organizaciones de pertenencia de la muestra de militantes entrevistados tomada para este artículo abarcó, en el caso argentino, a: redes del Partido Justicialista; sellos partidarios menores, como el Frente Grande; organizaciones que fueron identificadas durante el mandato de Néstor Kirchner como “organizaciones sociales”, como Barrios de Pie, luego confluida en Libres

acreditada. La primera, durante agosto y septiembre de 2013, en el Instituto de Filosofia e Ciências Sociais da Universidade Federal do Rio de Janeiro (IFCS-UFRJ). La segunda, durante diciembre de 2013 y enero de 2014, en la Fundação Getúlio Vargas (FGV), San Pablo.

6. Cabe destacar que los nombres utilizados para citar a los entrevistados son ficticios. Ello obedece a la decisión metodológica de preservar sus identidades.

7. Aunque el criterio escogido para delinear las generaciones, la década de inicio de su militancia juvenil, deriva, en la práctica, en cierta coincidencia etaria, ésta no se produce en todos los casos. Por ejemplo, tomemos el caso de dos entrevistadas, Ruth, en Argentina, y Marlene, en Brasil. Aunque sus edades son similares, Ruth pertenece a la "generación pos 2003", dado que se incorporó recién como militante juvenil en 2003, ya durante el gobierno de Kirchner, mientras que Marlene comenzó a militar en el PT durante la década del noventa, antes de la presidencia de Lula. 
del Sur (dentro del kirchnerismo hasta 2009); la Confederación General del Trabajo (CGT); y una serie de organizaciones militantes con distintos formatos y denominación -corrientes, movimientos, agrupaciones, espacios, etc.- que fueron surgiendo por fuera del PJ y reposicionándose en el interior del kirchnerismo, especialmente desde 2008, como La Cámpora, Nuevo Encuentro, Peronismo Militante, Kolina, Corriente Nacional de la Militancia y el Movimiento de Unidad Popular (MUP).

En Brasil, las entrevistas tomadas para la muestra incluyeron a partidos de la base de los gobiernos en cuestión, como el propio PT, el Partido Comunista de Brasil (PCdoB) y el Partido Democrático Laborista (PDT). En el caso del $\mathrm{PT}$, al tratarse de un partido de tendencias internas, se procuró el acceso a varias de ellas, como las incluidas en el campo mayoritario, "Construyendo un Nuevo Brasil" (CNB), u otras minoritarias como "Democracia Socialista" (DS) -y su campo más amplio de pertenencia, "Mensaje al Partido"- "Articulación de Izquierda" (AE), así como a entrevistados no pertenecientes orgánicamente a ninguna tendencia. Y, por fuera del espacio partidario, la muestra incluyó organizaciones como la Marcha Mundial de Mujeres (MMM), la CUT y el MST.

Así, la muestra de entrevistados para este trabajo se construyó siguiendo las particularidades de cada caso nacional. Por ejemplo, dado el peso respectivo de los militantes petistas en otras organizaciones del oficialismo en Brasil, la proporción de miembros del PT en la muestra también es alta. De modo inverso, la proliferación de espacios militantes kirchneristas al margen del PJ en Argentina llevó a que el espectro de organizaciones incluidas en la muestra allí fuera más amplio que en Brasil.

El análisis de las narrativas militantes en este trabajo aborda los procesos de interpretación que los entrevistados hacían de sus propias experiencias como mediados por creencias, actitudes y valores, concibiendo a sus testimonios como una selección y evaluación de los eventos descriptos (Sautu, 1999). En el caso de las generaciones que recuerdan y dan testimonio sobre su militancia juvenil en décadas previas, se toma esas narrativas, incluso, como una suerte de extracción de la práctica política pasada desde el presente o, en términos de González, como "pasado revisitado" (González, 2015).

Es por ello que, en términos de James (2004), si bien el testimonio oral es una ventana hacia aspectos subjetivos de la historia de los actores, el cristal estaría refractado y la visión que ofrece no es un mero reflejo transparente de sus sentimientos o vivencias (James, 2004, p. 128). Pero, aun desde esos reparos, es posible coincidir con el autor en que la calidad subjetiva del testimonio oral debe ser tratada como una "oportunidad única y no como el obstáculo a la objetividad histórica y el rigor empírico" (James, 2004, p. 127). También se toma en consideración el hecho de que los entrevistados, al ser militantes, actúan en el 
marco de espacios políticos orgánicos, en los cuales se produce una socialización y procesamiento colectivo del pasado y del presente, forjándose narrativas "oficiales" que coexisten y se retroalimentan con las concepciones y memorias construidas individualmente por los actores.

\section{Resultados}

A partir del análisis cualitativo de las entrevistas, las diferentes categorías emergentes fueron agrupadas y organizadas en torno a dos ejes generales. Por un lado, los sentidos e implicancias asociados, en las narrativas militantes, al compromiso y la actividad política. Ello, en términos de la dedicación y la relación (y tensiones) con la vida personal (trabajo, estudios, familia o afectos), las características asumidas por el vínculo político y la formación teórico-política de los militantes 8 . Y, por otro lado, y dado que se trataba de militantes oficialistas cuyas organizaciones de pertenencia contaban con una presencia institucional en el Estado, a través de cargos, manejo de recursos o difusión de programas estatales en la militancia diaria, se analizó la intersección entre la militancia y el Estado a través de las narrativas de los militantes en torno al fenómeno de profesionalización y también a las modalidades de articulación cotidiana (en quienes trabajaban en el Estado) entre las tareas político-organizativas y el desempeño en la función pública.

\section{a. Sentidos asignados a la militancia}

En lo que se podría denominar como "generación de los ochenta" (es decir, que inició su trayectoria militante como juventud en esa década), tanto en Brasil como en Argentina, era recurrente la noción de un militante de aquella época que habría exhibido una disposición a un conjunto de tareas hoy ya menos comunes entre el activismo político. Algunas actividades, entonces, habrían caído en desuso con el paso de los años, como el boca de urna en Brasil, que era la persuasión de los votantes en las proximidades de las escuelas de votación y que fue restringida incluso en la normativa. Otras aún eran realizadas en el presente, pero, en los relatos de esa generación del ochenta, los militantes más jóvenes se mostraban reticentes a participar de las mismas -en términos de Octavio (Movimiento Evita, antes PJ, 05/03/08), "los pibes te lo discuten más". En la generación pos 2003, ello se evidenciaba en el caso de Julián, por ejemplo, con

8. En el caso de las generaciones que comenzaron su militancia juvenil en los años ochenta y noventa, se ha procurado recuperar esos sentidos para aquellos períodos, así como para la actualidad, con testimonios y lecturas sobre el pasado y el presente. 
el timbreo, actividad de campaña consistente en ir puerta a puerta, pedir entrar para conversar con los vecinos y presentarles el material proselitista. Julián se rehusaba a realizarla, con estos argumentos:

"Dolores: ¿Y por qué decís que te gusta más la volanteada que hacer timbreo? Julián: Y porque el timbreo... me parece como muy invasivo, viste. Es como los Testigos de Jehová que van a las siete de la mañana a tu casa, viste, y te tocan el timbre...Para mí es lo mismo, ¿entendés? No da. Todo bien, loco, de las puertas de mi casa para afuera, acá es mi espacio [...].

Dolores: Y si la gente te deja, ¿pasás a la casa en el timbreo?

Julián: Nunca hice timbreo porque no me gusta. No, hicieron mis compañeros. Yo no hago timbreo porque no me gusta. [...] yo no hago porque no es una actividad que... tampoco es que tengo que estar laburando con todo. Hay cosas que me chupan un huevo [no me importan] y no las hago, por más que todos las hagan. Está bien, yo formo parte de este colectivo, pero prefiero ponerle ganas a lo que me gusta” (Julián, Nuevo Encuentro CABA, 15/11/13).

Este ejemplo no significa que en la generación pos 2003 todos hicieran solamente las actividades que más les gustaban y rechazaran otras. Más bien, el hallazgo para esta generación juvenil es la coexistencia entre, por un lado, quienes concebían todas las actividades como un deber militante y, por otro, quienes tenían esta mirada más laxa y de reticencia a llevar adelante algunas de ellas. Había, asimismo, actividades de campaña antiguamente militantes que ahora eran realizadas ya por empresas o personas contratadas, como los cabos eleitorais contratados en Brasil, o como las pintadas y "afichadas" en las paredes en Argentina, frecuentemente tercerizadas por empresas. Y hasta el significado e incidencia de estas actividades, como las pintadas, sobre el votante había pasado a ser menos influyente, por ejemplo, que la campaña en la televisión, según reflexionaba Javier, militante juvenil en los ochenta (Javier, PJ, 03/08/07).

Thais, de la generación pos 2003, también daba cuenta de la dilución de las actividades militantes de la campaña del pasado:

"De una cierta manera, creo que hoy en día, y en 2006 [su primera campaña como militante \, las campañas electorales están mucho más dependientes de los medios, del efecto mediático. Los materiales que se producen, los volanteos [reparto de panfletos en la vía pública] son más con personas pagas. Entonces, en cuanto militantes en 2006, nosotros contribuíamos pero desde una cierta nostalgia [saudosismo]. ¡Porque en el '89 eran militantes! No tenían dinero, tenían que ir a la calle a conversar con las personas. Y creo que eso es importante aún, hay que hacerlo, pero desgraciadamente creo que las campañas hoy están más...hay 
que tener dinero, muchos materiales, banderas, broches, camisetas y televisión" (Thais, PT y Marcha Mundial de Mujeres, 14/01/14).

Asimismo, era común en las narrativas de los militantes que se iniciaron en los ochenta (en ambos países) el énfasis en un modelo de militante voluntario, con un trabajo disociado de su organización de pertenencia, y hasta estudiando, que militaba todo el resto del tiempo (por las noches, los fines de semana, etc.). A ese perfil se lo consideraba, en las narrativas de esa generación, ya virtualmente extinto, frente a otro que describían, para el presente, cuyas tareas militantes aparecían más ligadas al Estado, como el desempeño en cargos públicos o el trabajo para un mandato (como asesores de algún legislador nacional o local). Leonele, profesor universitario y activista del PT desde los años ochenta, ilustraba ese diagnóstico de ocaso del militante voluntario y sus tareas y actividades típicas:

"Como militantes comunes del PT, nosotros hacíamos esas actividades electorales voluntarias. Boca de urna [hacer campaña en la puerta de los lugares de votación mientras la gente espera para votar] para los candidatos mayoritarios, pero principalmente participábamos de la lucha interna. Discusiones internas, en las previas [elecciones internas], por ejemplo, tomar una posición. Hicimos un boletín para difundir nuestras ideas. Otros núcleos también tenían eso. La cuestión es que sólo el nuestro siguió haciéndolo. En los años noventa había varios núcleos que hacían eso. Nosotros continuamos. Ahí, y esto es una opinión personal, creo que no existe más militancia de ese tipo en el PT en los últimos diez años. Ya no es posible" [el resaltado es propio] (Leonele, sin tendencia dentro del PT, 20/12/13).

Y tanto en la generación de la redemocratización como en la iniciada en los noventa ${ }^{9}$, se advertía la idea de que el compromiso político había sido mucho mayor que en el presente, en el que sus niveles serían más laxos. En reciprocidad, desde la generación pos 2003, mientras algunos destacaban una continuidad, un compromiso total y referenciado en las tradiciones históricas de su propio espacio de pertenencia (por ejemplo, el peronismo en Argentina y el petismo

9. Cabría aquí introducir una aclaración. En el caso argentino, en los militantes iniciados en los ochenta y noventa en el peronismo, podríamos distinguir dos grupos: los que continuaron militando en el PJ durante los noventa y los que se distanciaron en aquel entonces del partido frente a las reformas menemistas. En el primer grupo, tal vez conscientes de la denostación de aquel período por parte del propio gobierno kirchnerista, al que eran afines en el presente, la reticencia e incomodidad para recordar aquella década era notoria. Referenciaban, entonces, ese pasado, sobre todo, en términos de disciplina partidaria o necesaria adaptación a la época. Y rápidamente, privilegiaban referencias al presente más que al pasado, lo cual postuló un límite para comparar militancias juveniles de las tres generaciones. Esa omisión deliberada no tenía un correlato en el caso brasilero. 
en Brasil, o, de modo más amplio allí, la izquierda), otros aludían a la militancia del pasado y a sus patrones de acción como rígidos y cerrados, como Caique al referirse a la militancia de su partido en décadas previas (Caique, PCdoB-RJ, $15 / 08 / 13)$.

De todos modos, a la hora de describir su propio compromiso político como militantes juveniles, en las tres generaciones ('80, '90 y pos 2003) de ambos países predominaba la noción de que el mismo implicaba una dedicación total, completa (en términos de los entrevistados, "los siete días de la semana, las 24 horas"), absorbente y catalizadora, incluso, de tensiones con la vida personal (trabajo, estudios, afectos). Como en el ejemplo de Fabiano, de la generación de los ochenta (Corriente "Democracia Socialista", PT-RJ, 14/08/13) y Sandra, de los noventa (Libres del Sur, CABA, 28/06/08), que habían tenido que dejar de estudiar en la universidad mientras militaban (y debido a ello); o como Rufino, de la generación pos 2003, que describía la militancia del período en que aún no había ingresado a trabajar en el Estado como una suerte de fagocitación de otras esferas de su vida:

“Trabajar, militar y estudiar es una combinación letal. Letal, muy nociva. [ ...] la militancia exige, cuanto más te involucrás políticamente, te exige más tiempo. Y la dinámica política hace que vos pongas la política por sobre todas las demás cosas. [...] Te morfa [come] todo, los estudios y todo. Si tenés familia, te morfa la familia. Y no existe ni domingo, ni sábado, ni feriado, ni vacaciones, ni nada. No existe nada. Hay una actividad, te dicen que es importante, y tenés que estar. [ ...] El 'militante militante', son pocos los que llegan a ese grado pero, el 'militante militante', todo está sujeto a lo que decida la política” (Rufino, Peronismo Militante, CABA, 01/10/15).

En cuanto al carácter del vínculo político, se evidenciaba en los testimonios la flexibilización progresiva del mismo a lo largo de las tres décadas en cuestión. Los militantes iniciados en los ochenta, en ambos países, enfatizaban un proceso de fragilización y creciente inestabilidad del vínculo político (tanto en la relación de los votantes no organizados con su otrora partido de referencia, como en la propia militancia activa), llegando a sugerir incluso una especie de mercantilización del mismo y cierta lógica de criterios instrumentales basados en la circulación de recursos materiales o posibilidades laborales. Héctor, afirmaba, en ese sentido que:

"Los noventa, creo que corrompieron a la militancia. Si bien yo ya no estaba participando, siempre tuve vínculos, y en las internas del PJ tenía un precio el 
voto. Si eras un puntero y tenías 50 afiliados, por cada afiliado que llevabas a votar era una mercancía, y generó un tipo de militante político que después se volvió puntero $[\ldots]$ Y eso fueron cosas que quedaron, todavía vinculadas a la política. Uno estando al frente de una organización, te vinculás con...lo que te decía yo, vamos a construir a los barrios, pero sin embargo hay gente que se acerca a militar con la lógica de "bueno, pero ¿qué hay?” [a cambio de militar ]. [...] Antes estaba lo de los cautivos, porque mi familia es peronista soy peronista, sin mucha evaluación, ¿no es cierto? Una cosa más de identidad, era como automático, ahora lo que veo son militantes que están ahí al mejor postor” (Héctor, Kolina, antes PJ, $14 / 11 / 2013)$.

Vítor, por su parte, manifestaba que

Otro [efecto negativo] que se va a empezar a ver en el PT, como ya lo veo hoy, es de una clientela, parlamentarios, grupos políticos, liderazgos regionales que establecen una relación de patrón-empleado con sus, entre comillas 'militantes'. Un mandato de concejal en San Pablo dispone de un dinero mensual para contratación de personas [...] eso establece un vínculo que no es más un vínculo de un líder político con sus bases orgánicas. Es un vínculo de un líder que controla los empleos que atraen a una parte de su base militante (Vítor, Corriente Articulação de Esquerda, PT-SP, 19/09/20008).

Esta noción de Vítor parecía aparecer con más frecuencia en testimonios de miembros de corrientes internas del PT opositoras a la conducción del partido. Sin embargo, Enrique, militante de larga trayectoria petista y que sí pertenecía al denominado "campo mayoritario" del PT, también hablaba de un avance del individualismo y la ambición personal en el vínculo de los nuevos afiliados con el partido, y se preocupaba por el fenómeno de nuevos ingresantes que entraban al PT ya con "un interés electoral” (Enrique, Corriente Construindo um novo Brasil, PT-SP, 20/12/13). Es decir, aun con diferente intensidad y regularidad entre las distintas corrientes partidarias de pertenencia, el diagnóstico de la flexibilización y transformación del vínculo político (y militante) cobraba un peso significativo en la generación de los ochenta.

Entre los entrevistados iniciados en la militancia juvenil en la década del noventa, la advertencia sobre una personalización e informalización del vínculo político, así como sobre la creciente fluctuación del voto y las propias bases organizativas o redes -en términos de Maxi, del PJ, "hoy al compañero lo tenés acá, y mañana allá” (29/11/07)-, también estaba presente, junto con un lamento en torno a la creciente autonomización de candidatos y legisladores respecto de la organización de pertenencia. 
Esa lectura recorría incluso los relatos de militantes de diferentes organizaciones en ambos países, como el PT, el PDT, el PJ y el Frente Grande, que observaban una tendencia general de dilución de identidades partidarias y de informalización del lazo de representación. Por su parte, aunque también advertía un vínculo político fluctuante, la generación incorporada a la militancia luego de 2003, especialmente en el caso argentino, lo interpretaba, a menudo, de otro modo, como un subproducto coyuntural derivado de la manipulación mediática (que llevaba a los votantes a errores de información y a desconfiar del gobierno electo) o de la incomprensión del escenario político (cierta ingratitud, o la incapacidad de ver lo que el gobierno habría garantizado para sus propias vidas).

La cuestión de la formación política dentro de las organizaciones arrojaba narrativas más homogéneas en la generación que había iniciado su trayectoria de militancia juvenil en los ochenta que en las dos posteriores. En la primera, y más aún en Brasil que en Argentina, los entrevistados coincidían en identificar niveles de formación política considerablemente mayores en la militancia de aquellos años de redemocratización que en el presente. Mencionaban así la exigencia de lecturas, la formación teórica y la información que en el pasado eran requeridas para participar en discusiones internas, así como para llegar a cargos partidarios o de responsabilidad organizativa. Fabiano (Corriente Democracia Socialista, PT-RJ, 14/o8/13), por ejemplo, señalaba, para la actualidad, un debilitamiento de los cuadros y la existencia de militantes con altos cargos partidarios que en el pasado no hubieran siquiera permanecido como militantes. Wilhelmina, del PCdoB, lo veía, por su parte, en las discusiones internas:

"Creo que en esa época teníamos una disposición...porque las reuniones se hacían así. Se hacía un análisis de la coyuntura internacional, después de la de América Latina, y se analizaba nacionalmente para después ver lo local. Eso obligaba al militante a estudiar, a estar informado de lo que estaba pasando en ese momento. No podía ir a la reunión con una opinión personal. Para entender las protestas en la calle, no bastaba con estar en la calle. Tenía que estar estudiando, leyendo, informándose. [...]. Hoy ya no vivimos más eso. Vivimos reuniones muy atrasadas, de una urgencia que no te permite planificación, que no permite una visión general y analítica. Eso es un problema. Porque a veces las personas confrontan una posición con otra y ahí quien tiene un poco más de poder institucional conduce a una opinión” (Wilhelmina, PCdoB-RJ, 19/08/2013).

El testimonio de Wilhelmina, aunque pudiera, por supuesto, estar mediado, como en otros casos, por cierta idealización de su propia militancia de juventud, ilustraba diferentes problemáticas del presente. Por un lado, la "urgencia" 
relacionada con agendas organizativas diferentes a las del pasado (cuando estas organizaciones aún no eran parte de un gobierno), y cómo esa urgencia incide sobre las dinámicas internas y deliberación al interior de su partido (primando, en el momento del debate, las posiciones según la cuota de poder institucional de sus participantes, como se veía en su cita). Por otro lado, el deterioro en la formación cotidiana, la impulsada desde la organización y también las lecturas individuales ("estudiar", "estar informado”). La llegada al Estado y el masivo crecimiento de las organizaciones paralelo a esa inserción (con una concomitante flexibilización en el ingreso de nuevos miembros) eran señalados, en testimonios de aquella generación, como otros factores del deterioro progresivo en las instancias y niveles de formación militante.

En cambio, tanto dentro de la generación iniciada en la militancia en la década del noventa como de la incorporada a la política con posterioridad a 2003, era posible apreciar la coexistencia de dos narrativas diferentes. Por un lado, quienes advertían una escasez de instancias de formación actuales, como Luan (Mensaje al Partido-PT, SP, 11/12/13) y Caique (UJS-PCdoB, RJ, 15/08/13), en Brasil; o bien las veían como una tarea pendiente a desarrollar por su organización, como Aldo (Corriente Nacional de la Militancia, CABA, 13/11/13) en Argentina; o tenían dificultad para nombrar alguna instancia concreta de formación en las que hubiesen participado como militantes.

Por otro lado, se distinguían, sobre todo en Argentina, testimonios de entrevistados que enfatizaban los procesos de formación de cuadros militante en sus organizaciones, como Camila (MUP, Prov. de Buenos Aires, 13/11/13), de la generación de los noventa, que describía detalladamente una sucesión de “escuelas" o cursos de formación interna de dos meses de duración cada una, con jornadas de seis horas, materiales de lectura y exigencia de asistencia.

Cabe mencionar que en varios ejemplos de esa ponderación, por parte de los entrevistados kirchneristas, de las instancias propias de formación, emergía un elemento significativo para los interrogantes de este trabajo: la formación política de los militantes aparecía entendida desde alguna asociación con la inserción institucional en la gestión, con reiteradas referencias a la inclusión, en los cursos y talleres, de materiales que explicaban las principales medidas implementadas por el gobierno nacional ("los logros del modelo”) y cómo justificarlas.

Así, por ejemplo, Ruth, perteneciente a La Cámpora, recordaba cómo, en el proceso de consolidación de su organización, a fines de la década de 2000 , uno de sus miembros, economista, les daba clases semanales para "entender las medidas" que el gobierno tomaba. Y agregaba "hay montones de libros nuestros que vas a encontrar de formación política, sobre todo con las medidas que se iban tomando, y además en términos generales como para poder explicarle a la 
gente, llevarle a la gente las medidas” (Ruth, La Cámpora, provincia de Buenos Aires, 09/11/15).

\section{b. Concepciones sobre la militancia en el marco de la inserción en el Estado}

La relación con el Estado aparece como una dimensión imprescindible a la hora de comprender las prácticas y sentidos atribuidos a la actividad militante en espacios políticos que forman parte de conjuntos oficialistas. ¿Qué concepciones emergían en las narrativas de las distintas generaciones de militantes juveniles acerca de la militancia en relación directa con el Estado? Para ello, se pueden examinar dos cuestiones: el fenómeno de profesionalización de la militancia oficialista, y las modalidades de combinación cotidiana entre compromiso militante y desempeño en la función pública.

Este trabajo toma la definición de Ribeiro (2008) sobre la profesionalización de la militancia, que la identifica como la dedicación completa (o casi) del tiempo del militante a la política, obteniendo de ahí su sustento, y, en este caso, el fenómeno de asalarización de la actividad militante a través del Estado ${ }^{10}$. La cuestión de la profesionalización ${ }^{11}$ y sus posibles repercusiones para la militancia aparecía de modo espontáneo, recurrente y explícito en los testimonios brasileros, señalada como una mutación profundizada especialmente desde la llegada al gobierno federal, a partir de la cual se estaba configurando un nuevo perfil de militantes del PT y de otras organizaciones oficialistas, como la CUT y el PCdoB.

Así, en contraste con la figura del militante voluntario de los años ochenta, que cotizaba o contribuía financieramente a su organización de pertenencia de su propio bolsillo, se describía un nuevo tipo de militante profesionalizado, o con expectativas de estarlo en breve, y hasta transformado, por su cargo en el Estado, en su idiosincrasia -o incluso en su tránsito de base social, en términos de Vítor (Corriente AE, PT-SP, 19/09/08). Aunque esta antítesis era, sobre todo, formulada por la generación del ochenta (y, en menor medida, en la del noventa),

10. La profesionalización política se remonta a la sustitución, a fines del siglo XIX, de la "política de notables" por la "política de masas". En términos de Offerlé (2011), la "historia larga" de la profesionalización política es la de la "aparición, a menudo concomitante de la estabilización del sufragio 'universal' (primero masculino), de una categoría de agentes especializados y profesionalizados en la conquista y el ejercicio de un tipo particular de poder, el poder político".

11. En la muestra, aunque ello no fue un criterio excluyente procurado para su conformación, por lo menos un $67 \%$ de los entrevistados estaban, al momento de la entrevista, profesionalizados. Es decir, trabajando en el Estado o asalariados por sus organizaciones de pertenencia. 
aparecía también en algunos testimonios de la generación pos 2003, planteada como un problema derivado de la intersección entre militancia y Estado.

En Argentina, ese contraste aparecía con menos regularidad que entre los petistas brasileros. Un ejemplo de esa manifestación era el de Gonzalo, militante del PJ de La Matanza, profesionalizado al momento de la entrevista con un cargo en el gobierno municipal, que recordaba, en contraste con el presente, que "en los ochenta, la mayoría de los compañeros que estaban conmigo no trabajaban en la municipalidad”, y que él mismo había militado, durante los ochenta y noventa, sin trabajar en el Estado. "Por eso te digo que yo la militancia la viví desde otro lugar” (27/09/2007). Aquí, el recuerdo de sus inicios como militante voluntario aparecía contrapuesto con un presente criticado (el de los nuevos militantes ya más frecuentemente profesionalizados en el Estado), pero, también, en los hechos, con su propia inserción actual en el Estado municipal.

Más allá del ejemplo de Gonzalo, en el caso argentino, la regularidad de menciones a la profesionalización era menor que en Brasil. En términos generales, en el caso argentino, la cuestión de la generalización de la profesionalización estatalizada de la militancia se manifestaba de otro modo, más implícito e indirecto que en Brasil e, incluso, en ocasiones, naturalizado. Por ejemplo, a través de los testimonios, como los de Héctor (Kolina, prov. de Buenos Aires, 14/11/2013) o Ruth (La Cámpora, prov. de Buenos Aires, 9/11/2015) que resaltaban lo problemático de los intervalos o períodos en los cuales ese vínculo asalariado se había visto interrumpido, por ejemplo, ante la eventualidad de la ruptura política entre su propia organización o espacio y el gobierno en el cual habían sido funcionarios. Este último elemento no estaba delimitado generacionalmente.

Tal vez uno de los hallazgos más significativos en las narrativas militantes en torno a la cuestión de la profesionalización es que el rescate de la militancia del pasado frente a un presente más criticado aparecía, en ocasiones, más determinado por la organización de pertenencia (o corriente interna dentro de la organización, como en el caso del PT) que por la generación o momento de iniciación como militantes juveniles. En Brasil, la especial valoración del perfil del militante voluntario de los ochenta, se manifestaba más regularmente entre quienes integraban corrientes partidarias por fuera del denominado "campo mayoritario" del partido, "Construyendo un nuevo Brasil" (CNB).

La nostalgia, de ese modo, también operaba como un dispositivo de crítica a la corriente dominante, a la que se le atribuía el haber motorizado reformas perjudiciales sobre el modo de funcionamiento interno del partido y virajes en sus posiciones y políticas de alianzas desde mediados de los noventa. Y entonces, el problema específico de la crítica a la profesionalización generalizada de la militancia era introducido en las narrativas de militantes mayores, como Fabiano (Democracia Socialista o DS) y Vítor (Articulação de Esquerda o AE); pero también 
entre los que se incorporaron en los noventa, como Baltasar (DS), y en los que comenzaron a militar con posterioridad a la asunción de Lula, como Thais (DS) y Luan (Democracia Vermelha, dentro del campo Mensagem ao Partido). Y raramente aparecía, en cambio, en las narrativas de militantes de la conducción partidaria, como Pedro, de los ochenta, o Marlene de los noventa, ambos de la CNB-PT. El contraste o clivaje, en este punto, entonces, se delineaba más entre espacios políticos de pertenencia que entre generaciones.

En Argentina, el peso de referencias a la profesionalización estatalizada de la militancia era menor, e incluso no era, en muchos casos, problematizado, sobre todo en organizaciones nacidas a lo largo del mismo ciclo de gobiernos kirchneristas -y algunas, desde el seno de las propias dependencias estatales. En cambio, la crítica o aprensión frente al fenómeno de profesionalización de la militancia emergía más en miembros de organizaciones con trayectorias preexistentes al ciclo kirchnerista (2003-2015), que, al igual que el PT, la CUT y el MST en Brasil (aunque con identidades, tradiciones y prácticas diferentes), habían venido actuando en el pasado al margen del Estado. Por ejemplo, Santino, que había empezado a militar en los noventa en una organización que "resistía" frente a las políticas económicas menemistas y desde la que se concebía al Estado como un destinatario de protestas, decía, sobre la situación actual de las bases militantes kirchneristas (a las que pertenecía): "Estar actuando tanto adentro del Estado nos debilitó. [...] Los compañeros se convierten en empleados...Son militantes subordinados al nombramiento, a la continuidad en el trabajo en el Estado”. (Santino, Agrupación Felipe Vallese, antes PCCE, 13/11/2013).

$\mathrm{El}$ corte generacional, entonces, debería articularse, en este punto, con las diferencias en los orígenes y trayectorias de las organizaciones para comprender las valoraciones sobre las modalidades de militancia en torno al Estado en las narrativas militantes.

Además de la profesionalización, otro eje posible para examinar la militancia en el marco de la inserción estatal es cómo se combinaba o articulaba cotidianamente, en los propios militantes, su compromiso o tareas políticoorganizativas con el desempeño de las funciones de gestión. En este punto, los testimonios daban cuenta de una multiplicidad de modalidades diferentes de articulación. Esa diversidad de combinaciones prácticas desnuda el carácter reduccionista de cualquier interpretación unitaria o totalizante sobre la presencia de militantes en el Estado y exhibe, nuevamente, que el corte generacional no es suficiente para el análisis de este eje militancia-Estado.

Así, entre los entrevistados profesionalizados de la muestra, algunos manifestaban que, al estar trabajando en el Estado, habían tenido que dejar de abocarse a algunas tareas organizativas o partidarias. Otros definían los cargos públicos como espacios de construcción de su propia organización o corriente 
interna. Otros alegaban desarrollar gran parte de sus tareas militantes en territorio durante los fines de semana para poder cumplir con sus tareas de gestión durante la semana. Y finalmente, otros, sin reconocer una amalgama entre su organización de pertenencia y el Estado, describían, sin embargo, sus tareas laborales municipales en directa relación con su inserción políticopartidaria en los barrios. Y la lista de diferentes articulaciones halladas podría continuar.

En síntesis, mientras que para algunos la gestión implicaba que el compromiso se volcara enteramente al desempeño de la función pública (dejando de lado otros ámbitos y actividades previas de militancia), para otros, se trataba, en cambio, de una continuidad con las tareas organizativas militantes que ya se hacían antes -sólo que ya no voluntariamente sino de modo asalariado, y con un objetivo político-institucional (garantizar, por ejemplo, la reelección de algún legislador). Y en otros testimonios, la amalgama era naturalizada: era la presencia en la gestión lo que permitía llegar al futuro electorado y generar mediaciones personalizadas (“solución de problemas”) que luego se traducían en apoyo político.

En este punto, entonces, los hallazgos no habilitan un contraste significativo ni entre ambos casos nacionales ni entre las tres generaciones. Los ejemplos dan cuenta, por el contrario, de una amplia gama de sentidos y prácticas relativos a la articulación entre la militancia y la función pública. Cabrá, en trabajos posteriores, continuar desglosando esa multiplicidad de concepciones y prácticas en procura de poder establecer perfiles más nítidos.

\section{Conclusiones}

El estudio de la militancia juvenil oficialista en Argentina y Brasil planteado aquí combinó tres propósitos. Primero, un análisis sincrónico de dos militancias oficialistas específicas: las desarrolladas en torno a los gobiernos del PT en Brasil y a los gobiernos kirchneristas en Argentina. Segundo, de la mano del agrupamiento en tres generaciones, se desarrolló un análisis diacrónico sobre la transformación de los sentidos de la militancia y del vínculo político desde la redemocratización. Y tercero, al tomar como criterio el período de inicio en la militancia juvenil, se integró la dimensión de las juventudes y su compromiso político.

En ese triple propósito, es menester considerar las diferencias entre el legado del PT de los ochenta y noventa, cuando sólo llegó a administrar algunos gobiernos locales y estaduales, y el del peronismo, que integró la mayoría de los conjuntos gobernantes en el ámbito nacional y provincial desde la redemocratización. Sin 
embargo, las militancias oficialistas escogidas constituyen casos ricos para el análisis comparativo, dada la visibilidad pública y mediática que cobraron durante todo el período tomado (2003-2015 en Argentina y 2003-2016 en Brasil) y los debates que suscitaron en torno a la relación con el Estado.

Un primer eje trabajado en el artículo alude a los sentidos asignados a la militancia. En él se halló una tendencia general, en la generación que inició su militancia juvenil en los años ochenta, y en algunos casos de los noventa, a describir el compromiso y disposición a diferentes tareas y actividades militantes en el pasado como significativamente mayores que en el presente, resaltando incluso el carácter voluntario del militante de aquel entonces. En la generación que se incorporó a la militancia política después del 2003, es decir, ya como activistas dentro del oficialismo nacional, algunos compartían aquel diagnóstico, pero desde una lectura positiva del presente, resaltando una menor rigidez que en el pasado. Y otros, en cambio, inscribían el compromiso actual en continuidad con una tradición histórica de su espacio de pertenencia. De todos modos, en términos generales, prevalecía, en las tres generaciones, la definición del propio compromiso militante como total y absorbente, especialmente en términos de dedicación horaria.

En cuanto al vínculo político, su carácter crecientemente fluctuante exhibía un peso considerable en los testimonios, aunque desde explicaciones o interpretaciones diferentes sobre el fenómeno. Ésta podía variar desde la lectura de un proceso de fragilización del vínculo político (de electores, afiliados y también al interior de las bases militantes) hasta la de un problema coyuntural suscitado por los medios de comunicación.

Mientras que muchos entrevistados de la generación de los ochenta resaltaban la noción de un deterioro de los niveles de formación política (teórica, ideológica) de los militantes, que habría tenido lugar en las últimas décadas, tanto en la generación de los noventa como en la pos 2003, en cambio, coexistían dos narrativas opuestas sobre el presente: una que suscribía el mismo diagnóstico de la generación de los ochenta (caída en los niveles de formación de los militantes) y otra que señalaba y enfatizaba el desarrollo de instancias actuales de formación política militante, sobre todo, diseñadas con el propósito de entender y poder así difundir las medidas y políticas públicas del gobierno.

Un segundo eje que este artículo analizó se relaciona con la militancia desde su carácter oficialista y la consecuente posibilidad de inserción estatal. En este eje, se hizo especialmente visible un elemento: aunque el análisis por generaciones de militancia juvenil arrojó resultados muy sugerentes respecto a las concepciones contrastantes y tensiones intergeneracionales, es necesario combinarlo con otros criterios y dimensiones, puesto que algunas lecturas y sentidos atravesaban a los tres grupos. Y los clivajes, en cambio, aparecían más bien entre organizaciones 
(según su trayectoria, previa o simultánea a la inserción estatal, por ejemplo) o, incluso, en el caso del PT, entre corrientes o tendencias dentro del partido.

Así, las tres generaciones, por ejemplo, de militantes de la corriente Democracia Socialista (DS), compartían lecturas críticas sobre las transformaciones de la militancia petista (en términos del compromiso y la formación, o la generalización de la profesionalización y sus efectos potencialmente perniciosos). Esas críticas, por otro lado, estaban ausentes en los testimonios de militantes de la CNB, el campo político que ha venido conduciendo los destinos del partido.

Algo similar podría argumentarse en torno a la cuestión de la relación con el Estado entre organizaciones argentinas con trayectorias previas a la constitución del oficialismo kirchnerista y organizaciones nacidas, en cambio, durante el propio ciclo de esos gobiernos. Es decir, se estaría en algunos aspectos, ante socializaciones militantes -y consecuentes diagnósticos colectivos-diferenciadas en el interior del oficialismo (entre distintas organizaciones o entre corrientes intrapartidarias), que se reflejaban en lecturas similares, ya no según generación, sino según espacio de pertenencia.

\section{Referencias}

Amaral, O. (2010). As transformações na organização interna do Partido dos Trabalhadores entre 1995 e 2009, Tese de Doutorado em Ciência Política. Campinas: UNICAMP.

Bonvillani, A.; Palermo, I.; Vázquez, M.; Vommaro, P. (2008). Juventud y Política (1968-2008). Hacia la construcción de un estado del arte. Revista Argentina de Sociología, 6(11). Buenos Aires: Consejo de Profesionales en Sociología.

Brenner, A. K. (2011). Militância de jovens em partidos políticos: um estudo de caso com universitarios, Tesis de Doctorado en Educación. San Pablo: USP.

Carreirão, Y. (2008). Opiniões políticas e sentimentos partidários dos electores brasileiros. Opinião pública, Campinas, 14(2), 319-351.

Dagnino, E.; Olvera, A.; Panfichi, A. (orgs.). (2006). A disputa pela construção democrática na América Latina. São Paulo/Campinas: Paz e Terra/Unicamp.

Duverger, M. (1957). Los partidos políticos. México: Fondo de Cultura Económica. 
Garrido, N. (2012). Cibermilitancia 2.0. La juventud kirchnerista en la Argentina de hoy. Sociedad y Equidad (4). Santiago, Universidad de Chile.

González, G. (2015). Política y cotidianeidad: memorias del pasado reciente en Bahía Blanca (Argentina). Antípoda, Revista de Antropología y Arqueología (23), 65-85.

Gutiérrez, R. A. (2001). La desindicalización del peronismo. Política y Gestión, 2.

James, D. (2004). Doña María. Historia de vida, memoria e identidad política. Bs. As.: Manantial.

Kinzo, M. D. (2005). Os partidos no electorado: percepções públicas e laços partidários no Brasil. Revista Brasileira de Ciencias Sociais, 20 (57), 65-81.

Lacerda, A. F. de (2002). O PT e a Unidade Partidária como Problema. DADOS, Revista de Ciências Sociais, 45(1), 39-76.

Lameirão, C. (2009, 7-8 de mayo). "Sobre dirigentes públicos no governo Lula". II Congresso Consad de Gestão Pública. Conselho Nacional de Secretários de Estado da Administração, Brasília.

Levitsky, S. (2003). Transforming Labor-Based Parties in Latin America. Argentine Peronism in Comparative Perspective. Cambridge: Cambridge University Press.

Levy, C. (2012). Social Movements and Political Parties in Brazil: Expanding Democracy, the 'Struggle for the Possible' and the Reproduction of Power Structures. Globalizations, 9(6), 783-798.

Mainwaring, S. y Torcal, M. (2005). Party System Institutionalization and party system theory after the Third Wave of Democratization. Kellog Institute: Working Papers.

Manin, B., (1992). Metamorfosis de la representación. ¿Qué queda de la representación política? Caracas: Nueva Sociedad.

Marques, J. E. D. C. (2016). Juventude do Partido dos Trabalhadores: Institucionalização e militância juvenil. Goiânia. Tese para o Programa de Pós-Graduação em Sociologia. Faculdade de Ciências Sociais da Universidade Federal de Goiás. 
Mische, A. (1997). De estudantes a cidadãos: redes de jovens e participação política. Revista Brasileira de Educação (5/6). São Paulo: Editora Autores Associados.

Montero, J. R. y Gunther, R. (2002). Los estudios sobre los partidos políticos: una revisión crítica. Revista de Estudios Políticos (118), 9-38.

Moscovich, L. (2016). El doble estatus de los cuerpos burocráticos sub-nacionales: el balance entre gestión pública y acumulación política. Propuesta de análisis con evidencia de un país federal. Revista SAAP, 1O(1), 97-122.

Nicolau, J. (2015). Como aperfeiçoar a representação proporcional no Brasil. Revista Cadernos de Estudos Sociais e Políticos, 4(7), 219-239.

Norris, P. (2007). Political Activism: New Challenges, New Opportunities. Boix, C. and Stokes, S. (Eds.). The Oxford Handbook of Comparative Politics. Oxford: Oxford University Press.

Offerlé, M. (2011). Los oficios, la profesión y la vocación de la política. PolHis, 4(7), 84-99.

Oliveros, V. (2016). Making it Personal: Clientelism, Favors, and the Personalization of Public Administration in Argentina. Comparative Politics, 48(3), 373-391.

Pacheco, R. S. (2002, 8-11 de octubre). Mudanças no perfil dos dirigentes públicos no Brasil e desenvolvimento de competências de direção. VII Congreso Internacional del CLAD sobre la Reforma del Estado y de la Administración Pública, Lisboa.

Perelmiter, L. (2012). Fronteras inestables y eficaces. El ingreso de organizaciones de desocupados a la burocracia asistencial del Estado. Argentina (2003-2008). Estudios Sociológicos (Colmex), XXX(89), 431-458.

Pousadela, I. (2007). Argentinos y brasileños frente a la representación política. En Grimson, A. (comp.). Pasiones nacionales. Política y cultura en Brasil y Argentina. Bs. As.: EDHASA.

Pousadela, I. y Cheresky, I. (2004). (Eds.). El voto liberado. Elecciones 2003: Perspectiva histórica y estudio de casos. Buenos Aires: Biblos. 
Quirós, J. (2014). Militante. En G. Vommaro y A. Adelstein (coord.). Diccionario del léxico corriente de la Política Argentina. Palabras en democracia (19832013) (pp. 251-254). Polvorines: UNGS.

Ribeiro, P. J. F. (2008). Dos sindicatos ao governo: a organização nacional do PT de 1980 a 2005. Tese de Doutorado em Ciência Política. São Carlos: UFSCar.

Rocca Rivarola, D. (2011). En torno al líder: Relaciones y definiciones de pertenencia dentro de los conjuntos oficialistas de Luiz Inácio Lula Da Silva (2002-2006) y Néstor Kirchner (2003-2007): Tesis de doctorado en Ciencias Sociales, Buenos Aires: UBA.

Rocca Rivarola, D. (2015). Vínculos y formas de la militancia oficialista como un modo de adaptación a las condiciones de fluctuación política en Argentina y Brasil. Papeles de Trabajo, 9(15), 170-198. IDAES, Universidad de San Martín (UNSAM).

Rocca Rivarola, D. (2017). Saudade do partido: Referencias nostálgicas entre militantes de las bases de sustentación de los gobiernos argentinos y brasileros (2003-2015). Revista de Sociologia e Política, 25(62). Universidade Federal do Paraná.

Rocha, D. de C. (2009). Jeunes du Parti des Travailleurs et crise du militantisme. Agora Débats/jeunesses, 2(52), 89-104.

Samuels, D. (2004). From Socialism to Social Democracy: Party Organization and the Transformation of the Workers' Party in Brazil. Comparative Political Studies, 37(9), 999-1024.

Sautu, R. (1999). El método biográfico. Buenos Aires: Editorial de Belgrano.

Secco, L. (2011). História do PT. Granja Viana (SP): Ateliê Editorial.

Silva, M. K. y Oliveira, G. L. (2011). A fase oculta(da) dos movimentos sociais: trânsito institucional e intersecção Estado-Movimento, uma análise do movimento de Economia Solidária no Rio Grande do Sul. Sociologias, 13(28), 86-124.

Svampa, M. (2009). Introducción. In: M. Svampa (Ed.). Desde abajo. La transformación de las identidades sociales. Buenos Aires: Biblos. 
Tarrow, S. (2001). Trasnational politics: contention and institutions in International politics. Annual Review of Political Science (4), 1-20.

Vázquez, M. (2015). Juventudes, Políticas Públicas y Participación. Un estudio de las producciones socioestatales de juventud en la Argentina reciente. Bs. As.: GEU.

Vázquez, M., Rocca Rivarola, D. y Cozachcow, A. (2017). Fotografías de las juventudes militantes en Argentina. Un análisis de los compromisos políticos juveniles en el Movimiento Evita, el Partido Socialista y el PRO entre 2013 y 2015. En Vázquez, M.; Vommaro, P.; Núñez, P. y Blanco, R. Militancias juveniles en la Argentina democrática. Trayectorias, espacios y figuras de activismo. Buenos Aires: Imago Mundi.

Vázquez, M. y Vommaro, P. (2012). La fuerza de los jóvenes. Aproximaciones a la militancia kirchnerista desde La Cámpora. En Pérez, G. y Natalucci, A. Vamos las bandas. Organizaciones y militancia kirchnerista. Buenos Aires: Nueva Trilce. 